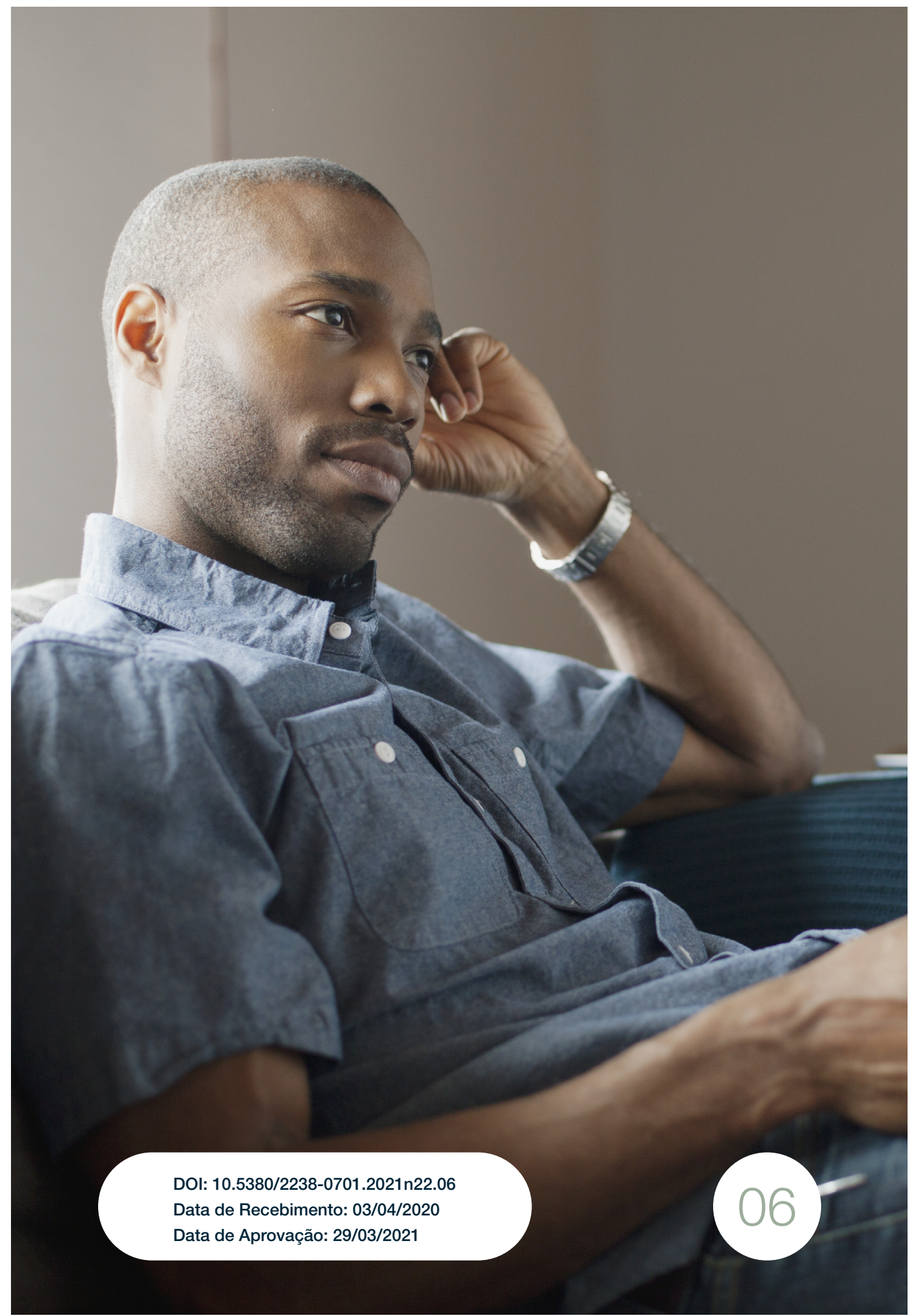


Mudanças na representação negra ao longo das reconfigurações da indústria televisiva dos Estados Unidos 


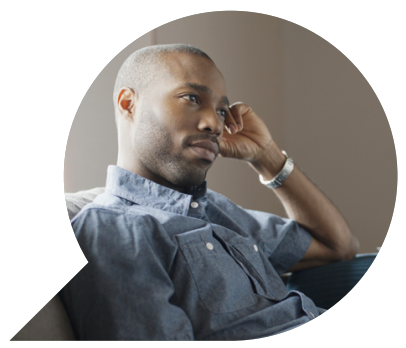

\section{Mudanças na representação negra ao longo das reconfigurações da indústria televisiva dos Estados Unidos}

\section{Changes in black representation throughout the reconfigurations of the United States television industry}

Cambios en la representación negra a lo largo de las reconfiguraciones de la industria televisiva de los Estados Unidos

BÁRBARA CAMIRIM ${ }^{1}$

Resumo: Compreendendo que as práticas da indústria televisiva afetam o conteúdo que chega ao espectador, este artigo tem o objetivo de investigar como as reconfigurações da indústria americana afetam a representação negra nesse meio. Para isso, apresentamos um panorama histórico desse processo, refletimos sobre o contexto atual e trazemos a Netflix como um exemplo de como isso é traduzido na atuação das empresas. Conclui-se que, contemporaneamente, o fenômeno de peak TV, a necessidade da criação de distinção por parte das empresas, o modelo do assinante e o alcance global dessas obras podem estar contribuindo para um maior investimento em obras de artistas negros. No entanto, a fragmentação da audiência e sistemas de recomendações podem estar limitando o

1 Doutoranda em Comunicação (UFF) e mestra em Comunicação e Cultura Contemporâneas (UFBA). 
alcance dessas produções, restringindo em parte o potencial de gerar discussões mais amplas na sociedade.

Palavras-chave: Representação negra; Televisão contemporânea; História da Televisão; Televisão dos Estados Unidos.

Abstract: Understanding that the practices of the television industry affect the content that reaches the viewer, this article aims to investigate how the reconfigurations of the American industry affect black representation in this medium. For this, we present a historical overview of this process, reflect on the current context, and bring Netflix as an example of how this is translated into the actions of companies. It is concluded that, contemporaneously, the phenomenon of peak TV, the need to create distinction by companies, the subscriber model, and the global reach of these works may be contributing to a broader investment in works by black artists. However, the fragmentation of the audience and recommendation systems may be limiting the reach of these productions, partly restricting the potential to generate broader discussions in society.

Keywords: Black Representation; Contemporary Television; Television History; US Television.

Resumen: Entendiendo que las prácticas de la industria televisiva afectan el contenido que llega al espectador, este artículo tiene como objetivo investigar cómo las reconfiguraciones de la industria estadounidense afectan la representación negra en este medio. Para ello, presentamos un panorama histórico de este proceso, reflexionamos sobre el contexto actual, y traemos a Netflix como ejemplo de cómo esto se traduce en las acciones de las empresas. Se concluye que, contemporáneamente, el fenómeno de los picos televisivos, la necesidad de crear distinción por parte de las empresas, el modelo de suscriptor y el alcance global de estas obras pueden estar contribuyendo a una mayor inversión en obras de artistas negros. Sin embargo, la fragmentación de la audiencia y los sistemas de recomendación pueden estar limitando el alcance de estas producciones, restringiendo en parte el potencial de generar discusiones más amplias en la sociedad.

Palabras-clave: Representación negra; Televisión contemporánea; Historia de la Televisión; Televisão de los Estados Unidos. 


\section{Introdução}

Descrevendo sua infância em um subúrbio da Filadélfia, nos anos 1960, Donald Bogle relembra do tempo livre passado em frente ao aparelho de televisão, onde via 'quase tudo' e começava a questionar as motivações e características dos raros personagens negros que apareciam na tela, embora se mantivesse encantado por aqueles performers (BOGLE, 2001). Experiência certamente muito diferente da descrita por Williams e Gonlin (2017), que analisam as discussões sobre a identidade negra na prática de co-viewing da série How to Get Away with Murder (ABC, 2014-) no Twitter.

Se, ao longo do tempo, reconfigurações na indústria televisiva mudaram a forma de se produzir, de se assistir e, até mesmo, de se entender televisão, algumas preocupações, como as ligadas às representações sociais, permanecem como objeto de estudos acadêmicos e foco de mobilização de ativistas. No entanto, é contraproducente separar essas dimensões, uma vez que as práticas da indústria afetam as histórias, imagens e ideias produzidas (LOTZ, 2007). Estabelecida essa premissa, nosso objetivo é pensar como as reconfigurações da indústria americana afetam a representação negra nesse meio, voltando, em um primeiro momento, nosso olhar para uma perspectiva histórica e, em seguida, investigando como as características da televisão contemporânea podem estar afetando as possibilidades de produção e circulação de narrativas criadas por artistas negros e/ou centradas em personagens negros. Para entender como esse processo se materializa na atuação das empresas, trazemos, como exemplo, uma breve reflexão sobre a Netflix.

O olhar para a indústria daquele país se justifica pela grande circulação transnacional de suas obras, em um contexto de cultura de séries (SILVA, 2014) e pelo aumento de estudos acadêmicos brasileiros que tem séries americanas como objeto de estudo (EVANGELISTA, 2018). A população negra desse país corresponde a cerca de 13\% da população total, enquanto no Brasil essa proporção soma cerca de 55\% (MAGENTA; BARRUCHO, 2020). Em ambos, a população negra é sub-representada na televisão e, embora a análise do caso brasileiro esteja fora do escopo deste artigo, essa invisibilização deve ser questionada, como já o fizeram Araújo (2000), Campos e Feres (2015), dentre outros. 


\section{Reconfigurações na indústria e seus reflexos na represen- tação negra}

É possível identificar, na história da televisão americana, diferentes períodos, cada um com suas especificidades em relação a tecnologias de distribuição, financiamento, práticas de produção e hábitos de consumo. Embora as periodizações simplifiquem processos que são complexos e que não são homogêneos em diferentes países, ainda assim elas são úteis como forma de se entender a história geral da televisão e para evidenciar que falar de televisão em tempos diferentes significa falar de diferentes formas de televisão (JENNER, 2018).

Desta forma, adotaremos a divisão proposta por Lotz (2007), baseada na indústria de televisão estadunidense. A autora propõe que a história dessa indústria pode ser dividida em três momentos: era das redes (de 1952 até meados dos anos 1980), transição multicanais (de meados dos anos 1980 até meados da década de 2000) e era pós redes (em curso desde meados da década de 2000).

$\mathrm{Na}$ era das redes, a televisão era dominada por três grandes redes comerciais (ABC, NBC, CBS), que distribuíam seu conteúdo por meio da radiodifusão e tinham um alcance de massa nos Estados Unidos. O suporte econômico dessas redes era proveniente de anunciantes, o que fazia com que a programação priorizasse os públicos que eles desejavam alcançar (LOTZ, 2018a). Nessa época, a lógica dominante era a da "programação menos censurável" e, embora as redes buscassem atingir uma cultura de massa homogênea, seus esforços eram mais direcionados para a classe média branca (LOTZ, 2007). As opções das audiências eram limitadas e as redes não demonstravam interesse em diferenciar suas programações ou criar identidades de marca distintas (LOTZ, 2007). Gray (2005) aponta que nessa época a televisão era construída discursivamente como formadora de um sentimento de identificação nacional e pertencimento. $O$ autor destaca que o sujeito dessa nação imaginada é branco e de classe média e que tal visão dependia da exclusão ou da domesticação da imagem de negros, latinos, asiáticos e indígenas.

As características desse período nos ajudam a compreender as escolhas de produção feitas e o lugar do negro na televisão do período. A influência dos anunciantes fica evidenciado pelo caso da série 
Three's Company (BOGLE, 2001). Em 1954, a imprensa noticiava um contrato de Sammy Davis Jr com a ABC, para a produção de uma sitcom sobre uma família de artistas negros, que teria números musicais e dramas, além de um coro formado por dançarinos e cantores brancos e negros. Um piloto foi produzido durante oito meses, contando com o investimento de 20 mil dólares, mas a série acabou engavetada pois a $A B C$ não conseguiu encontrar um anunciante que patrocinasse seu desenvolvimento.

Já a domesticação das imagens que pudessem deslocar o branco de classe média como sujeito da nação que pretensamente se formava pode ser percebida pelas duas sitcoms que traziam negros como protagonistas no início dos anos 1950: Beulah (ABC, 1950-1953) e Amos'n'Andy (CBS, 1951-1953), ambas já sucessos de audiência em suas versões originais, como programas de rádio. A primeira trazia uma mulher negra que trabalhava como empregada doméstica em um lar de pessoas brancas, cuja narrativa se restringia a resolver as confusões em que o casal branco e seu filho pequeno se envolviam, sem existência para além desses personagens (BOGLE, 2001). Cummings (1988) caracteriza essa personagem como uma repetição do papel estereotipado da mammy negra, que já existia no cinema, na literatura e no rádio. Já a segunda trazia protagonistas infantilizados, atrapalhados e frequentemente falando errado (BOGLE, 2001) e era uma imagem confortável para os brancos, uma vez que nenhum assunto social, racial, econômico ou político era discutido, ninguém sofria discriminação ou reclamava da falta de emprego e todos estavam aparentemente satisfeitos com suas condições de vida (CUMMINGS, 1988). Embora a audiência da época fosse concebida como passiva, essa série encontrou protestos de grupos de ativistas organizados (MONTGOMERY, 1989), o que no mínimo nos faz questionar essa concepção.

Ainda na era das redes, mudanças sociais marcadas pelo movimento pelos direitos civis trouxeram transformações na forma como os negros e negras apareciam na programação. Esse movimento trouxe um desafio para o ideal televisivo de unidade nacional, com a questão racial cada vez mais visível no imaginário nacional americano, e o gerenciamento da diferença se deslocou da exclusão para a assimilação, dentro de um ideal de pluralismo liberal (GRAY, 2005). Com o passar do tempo, a televisão iria escalar mais atores e atrizes negros em sua 
programação, em um esforço de refletir uma nação forçada a olhar para si mesma e reexaminar sua história, porém os mesmos programas se propunham a tranquilizar os espectadores brancos, mostrando que apesar das mudanças sociais e políticas, tudo ainda estava bem, o que em essência era uma negação dos conflitos e divisões raciais (BOGLE, 2001).

Na passagem para o período de transição multicanais, o discurso televisivo em relação a negritude vai se modificar. Esse período é caracterizado pelo surgimento de novas redes de radiodifusão (FOX, UPN e $W^{2}$ ) e de uma grande quantidade de canais a cabo. A experiência dos espectadores foi alterada principalmente pelo aumento de escolhas e do controle que se inicia na época da transição multicanais, e, se na era das grandes redes opções limitadas levavam programas a serem assistidos por uma considerável parcela da população, a explosão de opções de conteúdo na transição multicanais permitiu que os espectadores se isolassem cada vez mais em grupos com interesses específicos (LOTZ, 2007). Essa mudança na dinâmica competitiva da indústria se reflete nas estratégias de programação: ao invés de comissionar programas que sofreriam menos objeções, as redes e, principalmente, os canais a cabo cada vez mais desenvolveram programações para satisfazer membros específicos da audiência.

O suporte econômico dessas novas redes abertas é proveniente de anunciantes, porém, quando entraram no mercado, elas adotaram estratégias de contraprogramação, ou seja, oferecer conteúdo diferente em relação às três grandes redes tradicionais, investindo em programações orientadas a negros, como uma forma de conquistar audiências urbanas e jovens (GRAY, 2005) e de alcançar grupos demográficos que tinham menos acesso à tecnologia do cabo e do videocassete e que por isso assistiam mais televisão aberta (BRENT ZOOK, 1999). Já os canais a cabo poderiam ser acessados mediante a assinatura de um pacote (canais básicos) ou com o pagamento de um valor extra diretamente às empresas (canais premium). No primeiro caso, a receita dos canais era mista, vinda de anunciantes e assinantes, enquanto no segundo, a receita vinha apenas de assinantes. Esse novo modelo de financiamento traz demandas diferentes e altera as estratégias de programação de tais canais. Para justificar o pagamento extra, os canais a cabo premium precisavam oferecer algo que o espectador não pudesse

2 Em 2006, UPN e WB se uniram para formar a CW. 
obter com as redes abertas ou seu pacote de canais básicos, o que se traduziu na associação de suas marcas com as ideias de qualidade e risco, e uma das formas pela qual fizeram isso foi apostando na representação de minorias, de forma a atrair atenção crítica, gerar buzz e se diferenciar dos demais exibidores (FULLER, 2010). Nesse sentido, podemos pensar nas estratégias da $\mathrm{HBO}$ no período em que começou a se consagrar como produtora de séries de qualidade. Embora The Sopranos (HBO, 1999-2007) e Sex and the City (HBO, 1998-2004) tenham ficado na história da televisão como os marcos desse momento, Lotz (2018b) argumenta que foi o sucesso de Oz (HBO, 1997-2003) - uma série que se passava na prisão e contava com elenco multirracial - que abriu caminho para essas obras.

Embora o cenário desse período seja aparentemente mais vantajoso para os talentos e as audiências negras, não se pode dissociar o aumento de programas de estratégias industriais, que mudam de acordo com as demandas e percepções das empresas e seus executivos. A volatilidade dessa representação pode ser percebida quando observamos o processo pelo qual novas redes abertas passaram nos anos 1990:

Em meados dos anos 1990, as novas redes WB e UPN sobreviveram
pelo 'narrowcasting', exibindo programas endereçados para merca-
dos de nicho. (...) Uma importante estratégia dessas redes (como a
Fox antes delas) foi atrair espectadores negros que eram 'desassisti-
das' pelas redes maiores, e entregá-los para anunciantes interessados
nesse mercado. Porém, o grupo demográfico mais cobiçado era de
jovens brancos urbanos, e as novas redes cada vez mais focaram ne-
les, marginalizando sua audiência negra no processo. Elas limitaram a
programação negra para uma única noite ou a cancelaram completa-
mente (como a Fox fez com quatro dos seus seis programas negros
em 1994), deixando claro que a audiência negra não era mais uma
prioridade para novas redes (FULLER, 2010, p. 290, tradução nossa3).

Em relação aos canais a cabo, Fuller (2010) diz que a associação de negritude com qualidade e risco nos anos 1990 resultou em séries como Any Day Now (Lifetime, 1998-2002), Linc's (Showtime, 1998-2000) e

\footnotetext{
3 No original: "In the mid-1990s, new networks WB and UPN survived by 'narrowcasting', airing shows targeted at niche markets. (...) An important strategy of these networks (and Fox before them) was to draw black viewers, who were 'underserved' by the major broadcasters, and deliver them to advertisers who were interested in that market. But the most coveted demographic was young urban whites, and new networks increasingly focused on them, marginalizing their black audience in the process. They limited black programming to a single night or cancelled it outright (as Fox did with four of its six black shows in 1994), making it clear that black viewership was no longer a priority for new networks (FULLER, 2010, p. 290).
} 
Soulfood (Showtime, 2000-2004), em filmes feitos para a TV como Mandela (HBO, 1987), The Josephine Baker Story (HBO, 1991) e na minissérie Laurel Avenue (HBO, 1993), além da contratação, em meados dos anos 1990, de um diretor de programação étnica pela HBO, para desenvolver dramas, comédias, documentários e programação esportiva voltados para a audiência negra. A autora observa, no entanto, que, em fins dos anos 2000, a programação com personagens negros diminuiu nesses canais, que ao invés de promover a exposição que eles dão para minorias, mudaram seu foco, associando qualidade a assuntos históricos, em séries como The Tudors (Showtime, 2007-2010) e Deadwood (HBO, 2004-2006), e risco a neuroses da classe média branca, em programas como Weeds (Showtime, 2005-2012) e In Treatment (HBO, 2008-2010).

\section{Televisão contemporânea e estratégias de programação de minorias}

Desde meados dos anos 2000, transformações na indústria televisiva começam a indicar um novo período, no qual as mudanças nas normas competitivas e de operação da indústria se tornam tão proeminentes que práticas antigas não conseguem mais ser dominantes (LOTZ, 2007). Dentre as mudanças significativas desse novo cenário, estão a consolidação da internet como forma de distribuir conteúdo televisivo, a expansão do modelo de financiamento por assinantes, a possibilidade de entrega personalizada do conteúdo através de um catálogo, em contraposição às grades de programação, o aumento da circulação transnacional dos conteúdos e a customização em massa intermediadas por algoritmos e disponibilizada para os espectadores através dos sistemas de recomendação dos portais (LOTZ, 2017; 2018b). É importante destacar, no entanto, que os portais de internet - que de certa forma são a grande novidade desse período - não existem sozinhos no ecossistema de mídia contemporâneo. Redes abertas, canais a cabo básicos e premium permanecem em operação e relevantes, embora suas práticas estejam sempre em transformação para se adaptar a mudanças na dinâmica dessa indústria. A variedade de formas de distribuição, somada ao processo de fragmentação 
da programação, no qual mais programas são desenvolvidos, visando fatias menores da audiência, contribuíram na verdade para um período de abundância na programação televisiva, chamado informalmente no discurso jornalístico de Peak TV. Para Ladeira (2016), o que se observa na história da mudança das dinâmicas televisivas é uma passagem da escassez para o excesso.

Contemporaneamente, o audiovisual lida não mais com a escassez, seja de conteúdo, de infraestruturas ou de serviços de difusão. Passa a contar com redes de fibra ótica, transmitindo imagens em ultra-alta definição a partir de conexões em altíssima velocidade; pauta-se pelo manuseio de conteúdo através de aplicativos operando em dispositivos móveis, seguindo uma lógica de fluxo que se pretende irrestrito; refere-se a operações econômicas em hierarquias distintas, nas quais se torna difícil identificar certas divisões pregressas. O desenho se refere não a algum cenário futurista, mas redefine a forma de central relevância para a cultura durante o século XX (LADEIRA, 2016, p. 14).

Nesse ambiente altamente competitivo, redes tradicionais, canais a cabo e plataformas de streaming parecem ter retomado o interesse pela diferença cultural, com o objetivo de atrair atenção crítica e encorajar a participação nas mídias sociais (JEAN CHRISTIAN, 2019). Expandindo o argumento de Fuller (2010), de que a negritude foi operacionalizada por canais a cabo como forma de construir suas marcas e legitimar suas programações originais, Jean Christian (2019) argumenta que a interseccionalidade (histórias sobre pessoas que vivem nas margens das interseções de gênero, raça, sexualidade, etc) é usada para marcar as plataformas de streaming como 'aventureiras' e 'artísticas', apontando para Orange is the New Black ${ }^{4}$ (Netflix, 2013-2019) e Transparent ${ }^{5}$ (Amazon Prime, 2014-2019) como obras que estiveram na primeira leva de produções para plataformas de streaming e que serviram a esse propósito.

Outra consequência do excesso de programação é a necessidade ainda maior de sistemas de curadoria e organização do conteúdo. Nas transmissões lineares, isso ainda é feito a partir de uma grade de programação, com horário marcado para cada programa. Apesar disso,

\footnotetext{
4 Orange is the New Black, ambientada em um presídio feminino, ganhou atenção midiática pela centralidade e diversidade de suas personagens femininas, que incluía mulheres negras, latinas, lésbicas e transgênero. A série foi indicada a 20 Emmys (principal instância de consagração da televisão americana), ganhando quatro.

5 Transparent conta a história de uma mulher transgênero, já idosa, que decide se assumir para a família e para a sociedade. A série recebeu 29 indicações ao Emmy, ganhando nove.
} 
grande parte desses programas pode ser acessado de outra forma hoje em dia, por iniciativa das próprias empresas que expandem seus serviços, investindo também em plataformas de streaming, como por exemplo a CBS All Access, a HBO Go e, no caso brasileiro, a GloboPlay.

No caso das transmissões não lineares, o que é oferecido ao consumidor é um catálogo, que precisa ser organizado em uma interface que torne possível a navegação do usuário. A forma como essa interface vai ser organizada afeta a experiência (MASSAROLO; MESQUITA, 2018) e muitas vezes tal organização é personalizada, com base em algoritmos de recomendação. Para Hallinan e Striphas (2014), há o risco de sistemas de recomendação intermediados por algoritmos formem um ciclo no qual a conformação e não a inovação seja privilegiada.

A produção de recomendações sofisticadas produz uma maior satisfação do consumidor, o que produz mais dados do consumidor, o que por sua vez produz recomendações mais sofisticadas, e assim por diante, resultando - teoricamente - em um loop comercial fechado, no qual a cultura se conforma aos, mais do que confronta os, seus usuários (HALLINAN; STRIPHAS, 2014, p. 122, tradução nossa6).

Trazendo essas reflexões para a questão da representação das minorias, podemos pensar que programações com personagens negros, LGBTs, deficientes etc. irão suprir a demanda das audiências que os buscam ativamente, mas talvez nunca cheguem a ser oferecidas ao usuário cujo perfil de gosto traçado pelo algoritmo não as contempla. Situado dentro de um discurso liberal de escolha, o sistema de recomendação de certa forma limita o impacto social de certos textos, já que frequentemente a "programação politicamente ou socialmente subversiva só é consumida por segmentos da audiência que já concordam com as visões proporcionadas pelo texto" (JENNER, 2018, p. 103, tradução nossa7). Por outro lado, Lotz (2018a) alerta para que não se olhe para o passado de forma nostálgica, dizendo que o conteúdo da televisão americana já não tem características de um meio massivo há pelo menos 20 anos e que a cultura compartilhada de épocas anteriores,

\footnotetext{
6 No original: "The production of sophisticated recommendations produces greater customer satisfaction which produces more customer data which in turn produce more sophisticated recommendations, and so on, resulting - theoretically - in a closed commercial loop in which culture conforms to, more than it confronts, its users" (HALLINAN; STRIPHAS, 2014, p. 122).

7 No original: "politically or socially subversive programming is only consumed by audience segments that already agree with the views purported in the text" (JENNER, 2018, p. 103)
} 
quando a maioria dos espectadores consumia os mesmos produtos, "era alienante e estranha a muitos que agora veem a si mesmos e suas vidas representadas" (2018a, p. 38).

Outro aspecto das dinâmicas televisivas contemporâneas que afeta as possibilidades de representação é a maior circulação internacional das obras. Pensando do ponto de vista da indústria estadunidense ${ }^{8}$, Lotz (2018b) explica que:

O mercado internacional sempre foi uma parte importante do negócio da televisão. A população grande e relativamente rica dos EUA permitiu que a indústria televisiva sustentasse produções caras e recuperasse os custos no mercado doméstico sozinho. Vender programas para canais em outros países adicionava uma renda importante, mas não era uma consideração central ao criar os programas como se tornou em 2010. O orçamento crescente dos programas, audiências menores e fragmentadas e o crescimento de programas serializados que não vendem bem em syndication ${ }^{9}$ levou os estúdios a contar cada vez mais com o mercado internacional para cobrir os custos de produção (LOTZ, 2018b, p. 93, tradução nossa ${ }^{10}$ ).

Nesse sentido, Gray (2005) já no início dos anos 2000 apontava para uma mudança de perspectiva nos executivos de televisão norte-americanos, que sempre consideraram que a produção negra tinha lucros limitados, passando a considerar também o desempenho dessa programação em mercados mais distantes. Ou seja, em tese a maior circulação transnacional das séries televisivas seria um aspecto positivo para a produção negra - ao menos, para a produção negra estadunidense -, pois aumentaria o público potencial dessas obras e assim suas chances de receber investimento.

\footnotetext{
8 Embora estejamos adotando aqui o ponto de vista da indústria estadunidense, vale dizer que o processo de maior circulação internacional das obras não se restringe a este país.

9 O termo syndication, sem tradução exata para o português, refere-se ao sistema existente na TV americana em que "as séries são vendidas para exibição em estações locais ou canais a cabo, geralmente após atingirem a marca de 100 episódios ou cinco temporadas completas, de forma que possam preencher um horário na grade de programação durante todos os dias da semana sem a repetição excessiva dos mesmos episódios ao longo dos meses" (BIANCHINI, 2018, p. 70).

10 No original: "The international market has always been an important part of the U.S. television business. The large and relatively wealthy U.S. population has allowed the television industry to afford expensive productions and recoup costs in the domestic market alone. Selling shows to channels in other countries added important revenue, but this wasn't as central a consideration in creating shows as it became by 2010. Escalating program budgets, smaller and more fragmented audiences, and the growth of serialized programs that don't sell well in domestic syndication led studios to increasingly rely on international markets to cover the costs of production" (LOTZ, 2018b, p. 93).
} 
Por fim, outra característica da televisão contemporânea é a expansão do modelo do assinante, no qual o que importa é fornecer uma proposição de valor particular para o assinante (LOTZ, 2018a) - ou seja, oferecer conteúdo pelo qual ele sinta que vale a pena pagar - do que se conformar às necessidades de anunciantes e suas exigências de público a ser atingido. Para a produção negra, isso significa que uma obra pode ser economicamente viável caso haja um público disposto a assinar a plataforma para assisti-lo, independentemente da presença ou não de um anunciante interessado em vender seus produtos para esse mesmo público.

Feitas essas considerações, apresentamos agora uma breve análise sobre como certas características da produção televisiva contemporânea podem estar afetando as práticas de investimento da Netflix, para exemplificar como essas reflexões se materializam na atuação concreta das empresas.

\section{Netflix e representação negra}

A Netflix foi criada em 1997 como uma plataforma online para aluguel de DVDs e, desde 2007, iniciou seu serviço de streaming de conteúdos audiovisuais. Nesse primeiro momento, o catálogo da empresa era composto por obras licenciadas, que já haviam sido exibidas previamente de outras formas. No entanto, prevendo o aumento de competição no ramo de plataformas de streaming, começou a investir em produções próprias, tendo lançado, em 2012, a série Lilyhammer (Netflix/NRK1, 2012-2014), em parceria com a rede norueguesa de televisão aberta NRK1 (que exibiu a série na Noruega antes da própria Netflix disponibilizá-la em seu catálogo), e, em 2013, a primeira leva de produções exclusivas, das quais era a primeira exibidora, incluindo títulos como House of Cards (Netflix, 2013-2018), Orange is the New Black e Hemlock Grove (Netflix, 2013-2015).

Em um primeiro momento, a estratégia da Netflix em relação a suas produções originais tentava se distinguir por meio da exaltação da qualidade de suas produções (CASTELLANO; MEIMARIDIS, 201611; LOTZ,

11 No entanto, as autoras, já em 2016, questionavam estes discursos, dizendo que a Netflix não conseguia garantir tal distinção, tendo em vista sua busca por uma base massiva de assinantes. 
2018b). Hoje em dia, com a abundância de produções da empresa, pode-se dizer que a Netflix adota uma estratégia de "nicho conglomerado", buscando fornecer "um pouco de conteúdo para muitos segmentos diferentes da audiência" (LOTZ, 2018b, p. 158, tradução nossa ${ }^{12}$ ). Dentre esses segmentos, certamente está a audiência negra, como pode ser percebido pelo lançamento da campanha Strong Black Lead.

Essa campanha foi idealizada por funcionários negros da plataforma, com a intenção de promover e aumentar a cobertura de obras produzidas por profissionais negros ou endereçadas a esse público, além de criar um espaço nas redes sociais ${ }^{13}$ no qual essa audiência pudesse se encontrar (CAMIRIM, 2019). Para Bianchini e Camirim (2019), a campanha faz parte de uma série de ações promocionais da Netflix que visam associar a marca da empresa com uma promessa de mais diversidade nas produções. Ainda nesse sentido, Jane Shattuc (2020) destaca os grandes contratos com personalidades negras, como Shonda Rhimes, Dave Chappelle, Ava DuVernay, Kenya Barris e até mesmo com o casal Barack e Michelle Obama.

A abundância de produções audiovisuais observada no cenário contemporâneo indica tanto a necessidade de uma criação de marca distintiva quanto um processo de fragmentação da audiência, como explicitado anteriormente. Nesse sentido, a campanha parece servir tanto para atrair um segmento da audiência quanto para distinguir a marca Netflix. Em relação à segmentação da audiência, outros perfis específicos da Netflix parecem reforçar a hipótese. No Instagram, por exemplo, é possível encontrar perfis gerenciados pela empresa direcionados a diferentes nichos como Netflix is a Joke (voltado para a audiência que busca programação cômica), Most (audiência LGBT+), Con todo (audiência de latina dos Estados Unidos) e Netflix Family (audiência de pais e mães). Já em relação a marca, a campanha atua principalmente no sentido de associar a Netflix a ideia de respeito à diversidade. No entanto, cancelamentos repentinos de séries que trazem personagens marcados por distintos tipos de "diferença" expõem limitações desse discurso e sua dependência do interesse em retorno financeiro (CASTELLANO; PINHO; NORONHA, 2018; BIANCHINI; CAMIRIM, 2019).

12 No original: "a little bit of content for a lot of different audience segments" (LOTZ, 2018b, p. 158) 13 No Instagram: https:/wwww.instagram.com/strongblacklead/?hl=pt. No Facebook: https:/www.facebook. com/NetflixStrongBlackLead/. No Twitter: https://twitter.com/strongblacklead. Acesso em 18 mar. 2020. 
Para além dos cancelamentos, a própria forma como o catálogo funciona traz questionamentos a respeito do alcance da representação de minorias em plataformas de streaming. Nesse sentido, o sistema de recomendação mediado por algoritmos traz novas questões a serem exploradas. João Ladeira (2019) explica que inicialmente as recomendações da Netflix eram baseadas em notas atribuídas pelo público às obras, porém, com o tempo, esse mecanismo foi substituído pela tipificação de gêneros, com "divisões temáticas construídas através da catalogação minuciosa de cada produto" (p. 175), resultando em tipologias bem específicas, que formam microtags. Em seguida, é elaborada uma nova tipologia de gêneros alternativos, que consistem no reagrupamento dessas microtags, sendo essa etapa necessariamente atravessada pelo uso de máquinas. Além disso, os traços deixados pelo usuário quando em sua experiência com o material também viram dados para a plataforma. Essa coleta de dados se justifica pela promessa de atender as subjetividades dos indivíduos, por meio do mecanismo de sugestões, para que, supostamente, não seja necessário "aceitar em abstrato um material voltado para outros" (p. 176). Devido a essas escolhas algorítmicas, certos conteúdos ficam visíveis ao público, enquanto outros são invisibilizados, o que faz com que esses algoritmos tenham uma função de curadoria, arbitrando sobre a relevância de itens culturais (LADEIRA, 2019).

Embora esse sistema seja promovido pela Netflix como benéfico Ted Sarandos, chefe de conteúdo da empresa, já declarou que o futuro da televisão é feito de algoritmos baseados em gosto (CURTIN; HOLT; SANSON, 2014) -, é preciso pensar o que ele significa em relação aos regimes de representações. Para grupos historicamente invisibilizados ou marginalizados, o sistema pode significar exatamente o reforço desses padrões, agora justificados não por uma escolha de executivos e sim por uma intervenção algorítmica supostamente neutra. Isso porque é uma forma de limitar essas obras apenas à audiência que o busca ativamente, talvez nunca mostrando-as para a parte dos assinantes cujo dados não identifiquem como uma audiência potencial. Por outro lado, o alto nível de internacionalização da Netflix - a plataforma está disponível em 190 países e 21 línguas - faz com que mesmo uma audiência segmentada, um percentual pequeno da base de assinantes, significa uma quantidade grande de pessoas e, consequentemente, a viabilidade 
econômica da produção dessas obras. Nesse sentido, o modelo de financiamento baseado em assinantes também soma a essa viabilidade econômica, já que essas obras podem ajudar a expandir a base de assinantes neste público específico.

\section{Considerações Finais}

Propomos neste artigo uma abordagem de caráter teórico-reflexivo sobre as relações entre as reconfigurações da indústria televisiva, suas características atuais e as possibilidades de representação negra. Para isso, acionamos tanto a literatura sobre representações quanto a sobre as dinâmicas da indústria televisiva, pois entendemos que as escolhas de investimento e programação não são feitas em um vácuo a-histórico, e sim influenciadas pelo contexto institucional das mídias.

Como visto, há características ligadas ao ecossistema de mídia contemporâneo que podem estar afetando as possibilidades para a produção negra. Por um lado, a abundância de obras televisivas, a necessidade de criar distinção, o modelo de financiamento por assinantes e a consideração do alcance internacional das obras parecem criar um ambiente propício para o maior investimento em obras criadas e/ou protagonizadas por artistas negros. Por outro lado, o processo de fragmentação da audiência e os sistemas de recomendação por algoritmos indicam que o alcance dessas obras pode estar sendo limitado aos que já estariam pré-dispostos a apreciá-las, o que restringe (embora não acabe com) o potencial de gerar conversações públicas de maior abrangência.

Por fim, vale dizer que outras mudanças políticas e econômicas mais gerais também influenciam esse processo e, embora não tenha sido nosso objetivo explorá-las aqui, estudar esses fatores é um complemento ao entendimento do processo descrito neste artigo. 


\section{REFERÊNCIAS}

ARAÚJO, Joel Zito. A negação do Brasil: O negro na telenovela brasileira. São Paulo: Editora SENAC São Paulo, 2000.

BIANCHINI, Maíra; CAMIRIM, Bárbara. Mais histórias, mais vozes: Netflix e a promessa de diversidade na tela. Revista Latinoamericana de Ciencias de la Comunicacion, ALAIC, São Paulo, n. 31,2019 , p. 156-166.

BIANCHINI. Maíra. A Netflix no Campo de Produção de Séries Televisivas e a Construção Narrativa de Arrested Development. 2018. 219f. Tese (Doutorado em Comunicação e Cultura Contemporâneas) - Universidade Federal da Bahia, Salvador, 2018.

BOGLE, Donald. Primetime Blues: African Americans on network television. Nova lorque: Farrar, Straus and Giroux, 2001.

BRENT ZOOK, Kristal. Color by Fox: The FOX Network and the Revolution in Black Television. Nova lorque: Oxford University Press, 1999.

CAMIRIM, Bárbara. Apropriações de demandas por representatividade pelo discurso midiático mainstream: Uma análise da campanha Strong Black Lead. Anais do XVI Seminário de alunos de pós-graduação em Comunicação, PUC-Rio, Rio de Janeiro, v. 8, 2019, p. 20-31.

CAMPOS, Luiz Augusto; FERES Júnior, João. Televisão em cores? Raça e sexo nas telenovelas "Globais" dos últimos 30 anos. Textos para discussão GEMAA, n. 10, 2015, p. 1-23.

CASTELLANO, Mayka; MEIMARIDIS, Melina. Netflix, discursos de distinção e os novos modelos de produção televisiva, Contemporânea - Revista de Comunicação e Cultura, UFBA, Salvador, n. 2, v. 14, 2016, p. 193-209.

CASTELLANO, Mayka; PINHO, João Pedro; NORONHA, lara. "Netflix, eu te amo!": o capital emocional no relacionamento entre a empresa de streaming e os consumidores-fãs, Revista Fronteiras - Estudos Midiáticos, Unisinos, São Leopoldo, n. 3, v. 20, 2018, p. 404-417.

CUMMINGS, Melbourne S. The Changing Image of the Black Family On Television, Journal of Popular Culture, n. 2, v. 22, 1988, p. 75-85.

CURTIN, Michael; HOLT, Jennifer; SANSON, Kevin (eds.). Distribution Revolution: Conversations About the Digital Future of Film and Television. Oakland: University of California Press, 2014

EVANGELISTA, Raquel. Pesquisa em Ficção Seriada: uma proposta de revisão epistemológica baseada nas publicações da Intercom. In: Anais do 410 Congresso Brasileiro de Ciências da Comunicação, Joinville, SC, 2018.

FULLER, Jennifer. Branding Blackness on US cable television. Media, Culture and Society, n. 2, v. 32, 2010, p. 285-305.

GRAY, Herman. Cultural moves: African Americans and the politics of representation. Califórnia $e$ Londres: University of California Press, 2005.

HALLINAN, Blake; STRIPHAS, Ted. Recommended for you: The Netflix Prize and the production of algorithmic culture. New media \& society, n. 1, v. 18, 2016, p. 117-137, 2016. 
JEAN CHRISTIAN, Aymar. Beyond Branding: The value of intersectionality on streaming TV channels. Television and New Media, online first, 2019.

JENNER, Mareike. Netflix and the Re-invention of Television. Palgrave Macmillan, 2018.

LADEIRA, João. Imitação do excesso. Televisão, Streaming e o Brasil. Rio de Janeiro: Folio Digital: Letra e Imagem, 2016

. O algoritmo e o fluxo: Netflix, aprendizado de máquina e algoritmos de recomendações. Intexto, UFRGS, Porto Alegre, n. 47, set/dez, 2019, p. 166-184.

LOTZ, Amanda. The television will be revolutionized. New York and London: New York University Press, 2007.

Portals: A Treatise on Internet-Distributed Television. Ann Arbor, Michigan: Maize Books, 2017.

Um modelo para a produção de cultura: o modelo do assinante. In: CASTELLANO, Mayka; HOLZBACH, Ariane. TeleVisões: Reflexões para além da TV. Rio de Janeiro: E-Papers, 2018a, p.13-42.

We now disrupt this broadcast. How cable transformed television and internet revolutionized it all. The MIT Press, 2018b.

MAGENTA, Matheus; BARRUCHO, Luis. Protestos por George Floyd: em seis áreas, a desigualdade racial no Brasil e nos EUA. Notícias UOL, Londres, 08 de jun. 2020. Internacional, disponível em: https://noticias.uol.com.br/ultimas-noticias/bbc/2020/06/04/em-seis-areas-a-desigualdade-racial-no-brasil-e-nos-eua.htm. Acesso em: 12 mar. 2021.

MASSAROLO, João; MESQUITA, Dario. Autoprogramação e engajamento nas plataformas de vídeo sob demanda: uma análise da Netflix. In: CASTELLANO, Mayka; HOLZBACH, Ariane. TeleVisões: Reflexões para além da TV. Rio de Janeiro: E-Papers, 2018, p. 43-65.

MONTGOMERY, Kathryn. Target: Primetime: Advocacy Groups and the struggle over entertainment television. New York: Oxford University Press, 1989.

SHATTUC, Jane. Netflix Inc. and Online Television. In: WASCO, Janet; MEEHAN, Eileen. A companion to television. Second Edition. Nova Jersey, Wiley Blackwell, 2020, p. 145-164.

SILVA, Marcel. Cultura das Séries: forma, contexto e consumo de ficção seriada na contemporaneidade, Galaxia, 2014, n. 27, p. 241-252.

WILLIAMS, Apryl; GONLIN, Vanessa. I got all my sisters with me (on Black Twitter): second screening How to Get Away with Murder as a discourse on Black Womanhood. Information, Communication \& Society, n. 7, v. 20, 2017, p. 984-1004.

Recebido em: 03/04/2020 Aprovado em: 29/03/2021 


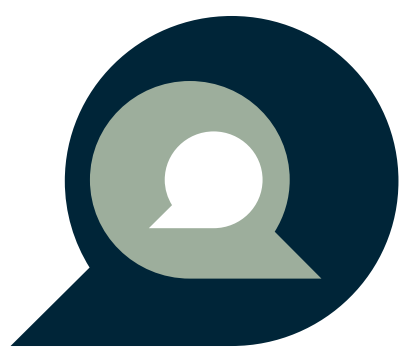

